First publ. in: Organic azides : syntheses and applications / eds. Stefan

Bräse .... - Chichester: Wiley, 2010, pp. 469-490

'The definitive version is available at www3.interscience.wiley.com'

\title{
Azides in Carbohydrate Chemistry
}

\author{
Henning S.G. Beckmann and Valentin Wittmann
}

Fachbereich Chemie, Universität Konstanz, Universitätsstr. 10, D-78457 Konstanz, Germany

\subsection{Introduction}

The first azide-containing sugar, a glycosyl azide, was reported in 1930 by Bertho. ${ }^{1}$ Since that time various methods have been developed for the introduction of azides at different positions of sugars. A survey of available methods is given in Section 16.2. Until the late 1970s, azides contained in carbohydrate derivatives were simply used as accessible synthons for amines because of their easily performed reduction to amines. Due to their stability against a variety of reaction conditions, azides often can serve as masked amines during the course of carbohydrate synthesis. The development of the diazo transfer reaction facilitated the use of azides also as temporary protecting group for amines. This was extensively applied during the preparation of aminoglycoside derivatives (Section 16.3).

Over the last three decades, azides became an important tool especially for the synthesis of glycopeptides and -proteins. In 1978 Paulsen et al. developed the 'azide method' for the preparation of 1,2-cis-glycosides of glycosamine derivatives using 2-azido-2-deoxydonors (Section 16.4). This reaction is widely used for the synthesis of $O$-linked glycosyl amino acid building blocks. In $N$-glycoproteins, the glycan chains are attached to the protein via a $\beta$-glycosyl amide. Staudinger-type reactions offer a convenient access to such structures and are applied since the 1990 s for the synthesis of $\alpha$ - and $\beta$-glycosyl amides directly from glycosyl azides (Section 16.5).

An enormous impact on the field of glycobiology during the last decade had the development of two bioorthogonal reactions based on azides: the copper-catalyzed azidealkyne $[3+2]$ cycloaddition and the Staudinger ligation. Together with the possibility of in vivo incorporation of azide and alkyne tags into glycans and proteins, these reactions offer new options for selective labeling and manipulation of biomolecules even within

Organic Azides: Syntheses and Applications Edited by Stefan Brase and Klaus Banert

Konstanzer Online-Publikations-System (KOPS)

URN: http://nbn-resolving.de/urn:nbn:de:bsz:352-opus-110645

URL: http://kops.ub.uni-konstanz.de/volltexte/2010/11064 
living cells. Especially the azide-alkyne cycloaddition has been extensively applied for the chemical synthesis of neoglycoconjugates such as glycopeptide and glycoprotein mimics or multivalent glycoclusters (Section 16.6). Metabolic oligosaccharide engineering uses the biosynthetic pathways for the introduction of azide- (and alkyne-)tagged sugar moieties into the glycans of cells that can subsequently be labeled by a detectable probe. This approach is discussed in Section 16.7.

\subsection{Synthesis of Azide-Containing Carbohydrates}

A common way for the introduction of azides into carbohydrates is the nucleophilic replacement of leaving groups by the azide ion. These reactions can be divided into three groups: substitutions at the anomeric center leading to glycosyl azides, substitutions at primary, and substitutions at secondary carbon atoms.

A widely used method for the preparation of glycosyl azides ${ }^{2-4}$ is the conversion of acetylated halogenoses, such as $\mathbf{1}$, by treatment with sodium azide based on Bertho's initial work (Scheme 16.1A).' While homogeneous one-phase reactions in DMF often require elevated temperatures, ${ }^{5}$ phase-transfer catalysis enables milder conditions. ${ }^{6}$ One limitation of this methodology is the instability of glycosyl halides. Thus, sequential onepot procedures have been developed that avoid the isolation of glycosyl halides. ${ }^{7}$ An alternative, which circumvents the preparation of glycosyl halides completely, is the direct conversion of glycosyl acetates into the corresponding glycosyl azides using trimethylsilyl azide under Lewis acid catalysis (Scheme 16.1B). ${ }^{8}$ Glycosyl azides with 1,2-transconfiguration are easily obtained by the described methods using acyl protecting groups due to their neighboring group participation. Glycosyl azides with 1,2-cis-configuration can be prepared from 1,2-trans-glycosyl halides in an $\mathrm{S}_{\mathrm{N}} 2$-type reaction or from etherprotected glycosyl acetates by treatment with trimethylsilyl azide..$^{2-4}$

A
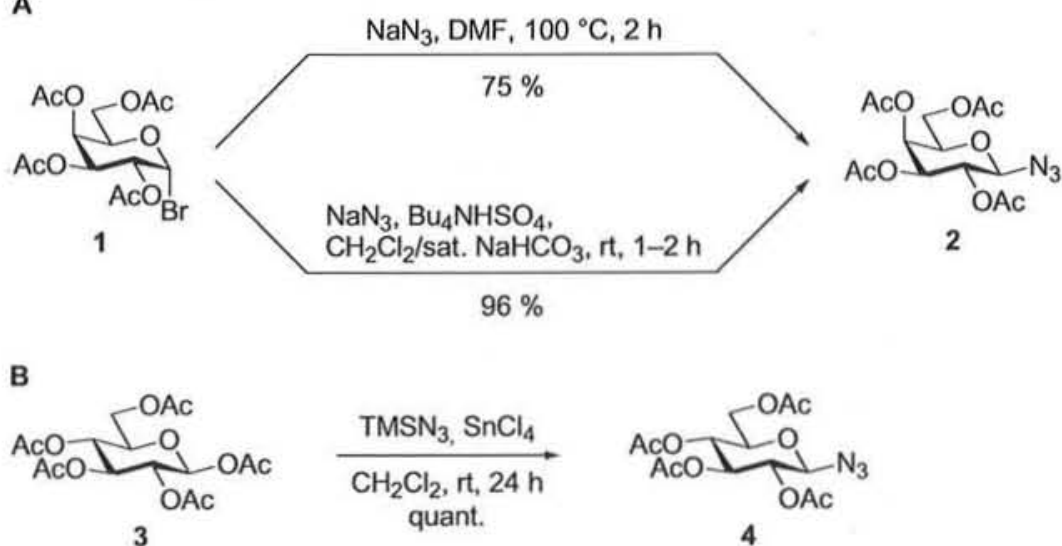

Scheme 16.1 Preparation of glycosyl azides from (A) peracetylated glycosyl halides under classical homogeneous conditions ${ }^{5}$ and under mild phase-transfer catalysis ${ }^{6}$ and (B) from peracetylated sugars $^{9}$ 
The introduction of azides at the primary carbon of carbohydrates is conveniently carried out by an $\mathrm{S}_{\mathrm{N}} 2$ reaction. The generation of a good leaving group, such as a sulfonate, is often possible in a selective way without need for protection of the secondary hydroxy groups as was shown for GlcNAc derivative 5 (Scheme 16.2). ${ }^{10}$ Subsequent substitution with sodium azide usually proceeds at elevated temperatures with good yields.

In contrast, $\mathrm{S}_{\mathrm{N}} 2$ reactions at secondary carbons of the sugar ring system are more complex. The success of such reactions is strongly dependent on the type of sugar (stereochemistry), the position at which the $\mathrm{S}_{\mathrm{N}} 2$ reaction is carried out, anomeric configuration, and used protecting groups. Nevertheless, this approach is widely applied for the introduction of azido groups at the ring system. For instance, the mesylate of glucoside 7 was substituted yielding 4-azido galactoside 8 under inversion of configuration (Scheme 16.3)."

Epoxides are also useful precursors for the incorporation of azido groups by nucleophilic attack. According to the Fürst-Plattner rule, ${ }^{12}$ ring opening of sugar epoxides by azide ions preferentially leads to the diaxial product. For instance, 2-azido compound $\mathbf{1 0}$ is obtained regioselectively by opening of Cerny epoxide 9 with sodium azide (Scheme 16.4) ${ }^{13}{ }^{10}$ was further converted into the suitably protected glycosyl donor 11 , which was applied in the synthesis of a heparan sulfate synthon by 1,2-cis-glycosylation (cf. Section 16.4).

Azides can also be introduced by radical addition to glycals. The classical azidonitration, developed by Lemieux et al. in 1979, is a powerful method for the preparation of

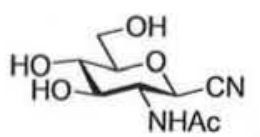

5

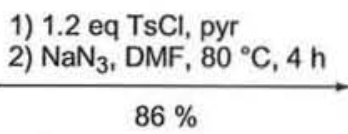

$86 \%$

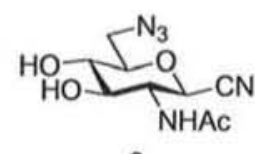

6

Scheme 16.2 Regioselective introduction of an azido group at the primary carbon of 5 via nucleophilic replacement of a sulfonate intermediate ${ }^{10}$ pyr $=$ pyridine

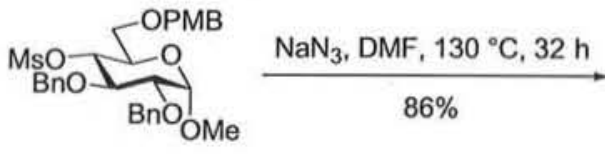

7

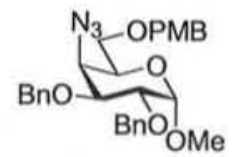

8

Scheme 16.3 Replacement of a mesylate by an azido group under inversion of configuration at a secondary center of the sugar ring ${ }^{11}$

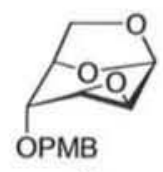

9

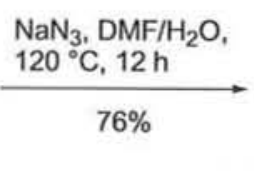

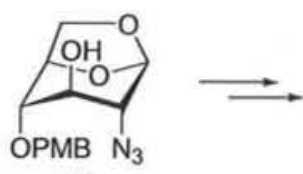

10

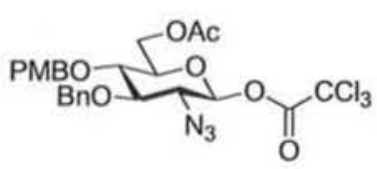

11

Scheme 16.4 Regio- and stereoselective opening of Cerny epoxide 9 leads to 2-azido compound 10, which can be further converted into glycosyl donor $\mathbf{1 1}^{13}$ 


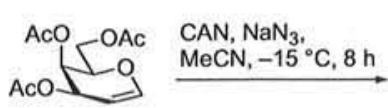

12

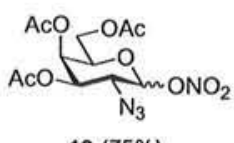

$13(75 \%)$

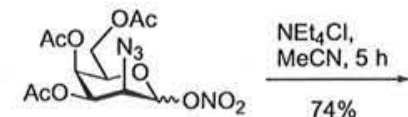

$14(8 \%)$

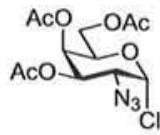

15

Scheme 16.5 Azidonitration of galactal 12 leads to an epimeric mixture of the 2-azido-1nitro-pyranoses 13 and 14 from which glycosyl donor 15 can be prepared directly. ${ }^{14}$ $C A N=\operatorname{cerium}(I V)$ ammonium nitrate

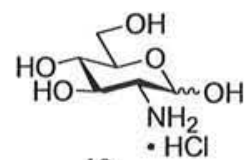

16
1) $\mathrm{TfN}_{3}, 1 \mathrm{~mol} \% \mathrm{CuSO}_{4}, \mathrm{~K}_{2} \mathrm{CO}_{3}$, $\mathrm{CH}_{2} \mathrm{Cl}_{2}, \mathrm{MeOH}, \mathrm{H}_{2} \mathrm{O}, 15 \mathrm{~min}$

2) $\mathrm{Ac}_{2} \mathrm{O}, \mathrm{DMAP}$, pyr

$82 \%$

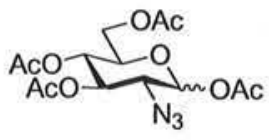

17

Scheme 16.6 Typical procedure for the Cu(II)-catalyzed diazo transfer. ${ }^{26}$ DMAP $=4$ (dimethylamino)pyridine

2-azido sugars that is still frequently used (Scheme 16.5) ${ }^{14}$ It is especially useful for the synthesis of those 2-azido derivatives, whose corresponding glycosamines lack accessibility from natural sources as in the case of galactosamine. However, while the reaction is highly regioselective, in most cases epimeric mixtures of the 2-azido compounds are formed. The ratio of the epimers strongly depends on the employed glycal substrate. ${ }^{15}$ The obtained 1-nitro-pyranoses can easily be converted into glycosyl donors, such as glycosyl halides, ${ }^{14}$ trichloroacetimidates, ${ }^{16}$-pentenyl glycosides,${ }^{17}$ or thioglycosides,${ }^{18-20}$ which are valuable building blocks for the preparation of 1,2-cis glycosides of $\mathrm{N}$-acetylglycosamines (cf. Section 16.4). Similar methods for the synthesis of 2-azido sugars using radical addition to glycals are the azidochlorination ${ }^{21}$ and the azidophenylselenation. ${ }^{22,23}$

Another possibility for the synthesis of organic azides is the diazo transfer using triflyl azide. ${ }^{24}$ In contrast to the methods described above, not the entire azido group is incorporated into a molecule but an $\mathrm{N}_{2}$ moiety is transferred onto an existing amine under retention of configuration. The first diazo transfer onto amino sugars was reported in 1991 by Vasella et al..$^{25}$ They treated different unprotected glycosamines with freshly prepared triflyl azide under basic conditions. After subsequent acetylation, the 2-azido sugars were isolated in good yields. This methodology was further improved by the addition of catalytic amounts of copper sulfate which leads to a much faster and more reliable reaction (Scheme 16.6). ${ }^{26,27}$ Using the diazo transfer, it is possible to employ azides not only as amine synthons but also as temporary protecting groups for amines. This has been applied for example to the synthesis of aminoglycosides (Section 16.3), heparan sulfate fragments, ${ }^{28}$ heparin fragments, ${ }^{29,30}$ hyaluronan neoglycopolymers,${ }^{31}$ and $\mathrm{N}$-acetylneuraminic acid derivatives. ${ }^{32}$

\subsection{Azides as Protecting Groups during Aminoglycoside Synthesis}

Protecting groups commonly employed for masking amino groups include alkyl carbamates such as benzyl-, tert-butyl-, and 9-fluorenylmethyl carbamates. If used for the 
protection of molecules containing multiple amino groups, however, carbamate protecting groups can seriously complicate the interpretation of NMR spectra. This is due to the occurrence of $E / Z$ rotamers that are in slow interconversion leading to multiple sets of signals. The use of azides as protecting groups circumvents this problem. Azides are easily reduced to amines, for example by catalytic hydrogenation or by reaction with thiols or complex hydrides. ${ }^{4.33,34} \mathrm{~A}$ widely applied method in carbohydrate chemistry is the Staudinger reduction using triaryl- or trialkylphosphines. ${ }^{35}$ This mild procedure enables the selective reduction of azides in the presence of esters and benzyl ethers which are frequently used as $\mathrm{OH}$-protecting groups. Furthermore, azides can be directly converted into carbamate-protected amines using a variant of the Staudinger reaction (cf. Section $16.5){ }^{27,36,37}$

Aminoglycosides are highly potent, broad-spectrum antibiotics, containing several amino groups presented on an oligosaccharide-like core. ${ }^{38-40}$ Due to the appearance of bacterial strains resistant to these drugs and due to their relatively high toxicity, the synthesis of aminoglycoside derivatives with improved properties is of great interest. ${ }^{41}$ Several syntheses of aminoglycoside derivatives using azides as amine protecting groups were reported, ${ }^{42,43}$ for instance the preparation of analogs of neomycin B as shown in Scheme $16.7 .^{27,44,45}$ Starting from commercially available neomycin B (18), all six amino groups were converted into azides by diazo transfer. After chemical derivatization of the structure, amines were regenerated by Staudinger reduction.

In the course of these studies, it was observed that the regioselective reduction of a single azide of multiple azide-containing molecules is feasible if only one equivalent of phosphine is used. ${ }^{27}$ Reduction of neamine derivative $\mathbf{2 3}$, for example, gave mono-amine 24 in a yield of $46 \%$ (Scheme 16.8). Strong evidence was presented that the selectivity is primarily determined by electronic factors with electron-deficient azides being reduced more rapidly and efficiently than electron-rich azides. In compound $\mathbf{2 3}$ this is the case for

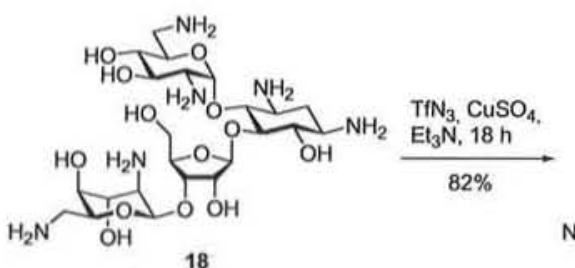

18
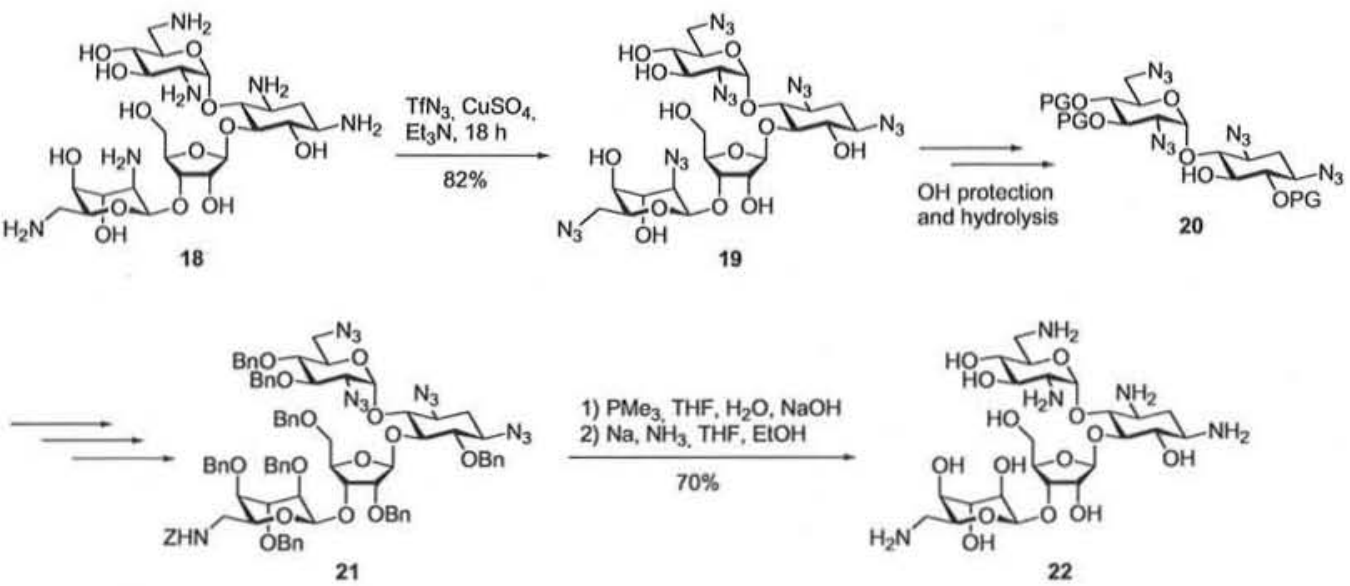

Scheme 16.7 Synthesis of aminoglycoside derivative 22 using azides as protecting groups for amines. First, the amino groups of $\mathbf{1 8}$ were converted into azides by diazo transfer. ${ }^{27}$ After chemical remodeling of the aminoglycoside (one amino group was replaced by a hydroxy group), the amines were regenerated by Staudinger reduction ${ }^{44}$ 


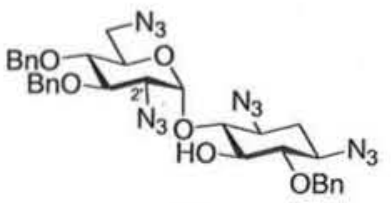

23

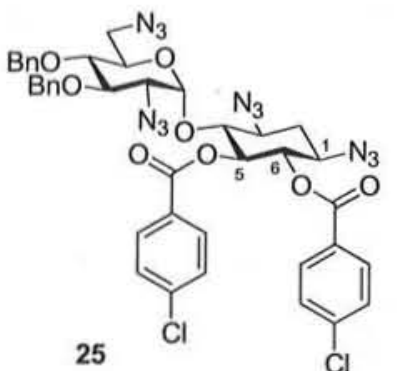

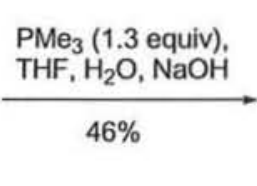

$\mathrm{PMe}_{3}$ (1.1 equiv), toluene, Boc-ON, $-78^{\circ} \mathrm{C}$ to $10^{\circ} \mathrm{C}$

$45 \%$

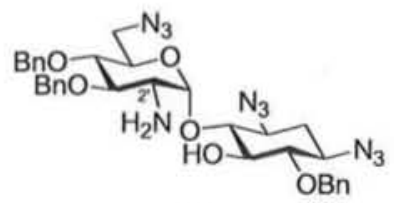

24

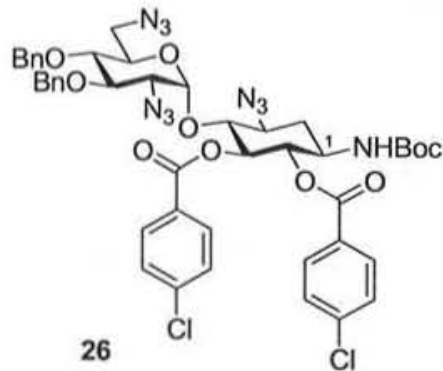

Scheme 16.8 Regioselective reduction of tetra-azides $23^{27}$ and $25.46,47$ Boc-ON $=2$ (tert-butoxycarbonyloxyimino)-2-phenylacetonitrile

the 2 -azide adjacent to the anomeric center. It was shown that the regioselectivity can be predicted on the basis of ${ }^{15} \mathrm{~N}$ and, to some extent, ' $\mathrm{H}$ NMR chemical shifts. Consequently, by introduction of electron withdrawing 4-chlorobenzoyl protecting groups in the 5- and 6-position, the selectivity can be tuned in favor for reduction of the 1-azide $(25 \rightarrow 26)^{46,47}$

\subsection{Azides as Non-Participating Neighboring Groups in Glycosylations}

Although 1,2-cis glycosides of 2-amino-2-deoxysugars are less frequently found in natural products compared to their 1,2-trans isomers, they are a common motive in important structures. In mucin-type $O$-glycoproteins, e.g. the glycan chains are attached to protein via an $\alpha$-glycosidic linkage of $N$-acetyl-D-galactosamine to the $\beta$-hydroxy group of either serine or threonine, and $\alpha$-glycosides of 2-acetamido-2-deoxy-D-glucose are found in the glycosaminoglycan heparan sulphate. ${ }^{48-51}$ For the preparation of these 1,2-cis glycosides, the commonly employed $\mathrm{N}$-acyl protecting groups are not suited because they lead to 1,2-trans products 29 via neighboring group participation (Scheme 16.9A). ${ }^{15.52 .53}$ In 1978 Paulsen et al. showed that 2-azido-2-deoxy-glycosyl halides are suitable donors in 1,2-cis glycosylations. This approach preferentially leads to $\alpha$-glycosides 32 either directly from $\beta$-glycosyl halides 30 (Scheme $16.9 \mathrm{~B})^{54,55}$ or by in situ anomerization ${ }^{56}$ of $\alpha$-glycosyl halides 33 (Scheme 16.9C). ${ }^{57}$ Since then, the azide method has been widely used ${ }^{15,52,58-62}$ and expanded by use of other glycosyl donors, such as trichloroacetimidates, ${ }^{16} n$-pentenyl glycosides, ${ }^{17}$ and thioglycosides ${ }^{18-20}$ just to name a few. The required 2-azido-2-deoxy sugars are usually prepared by azidonitration of glycals or by diazo transfer reaction of the corresponding glycosamines as described above. After glycosylation, the azide can 
A<smiles>[R]C(=O)NC1COC(OC([R])=O)C1[X]C([R])O</smiles><smiles>[R]C1NC2CCCCC(CC2)O1</smiles><smiles>[R]OC1OCC(C([R])C)CCC1NC([R])=O</smiles>

B

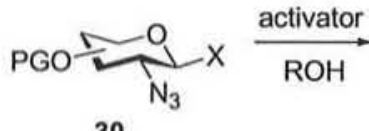<smiles>[R]OC1COCC(O[R6])C1[N+](=O)[O-]</smiles>

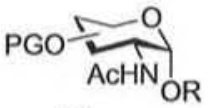
31

c

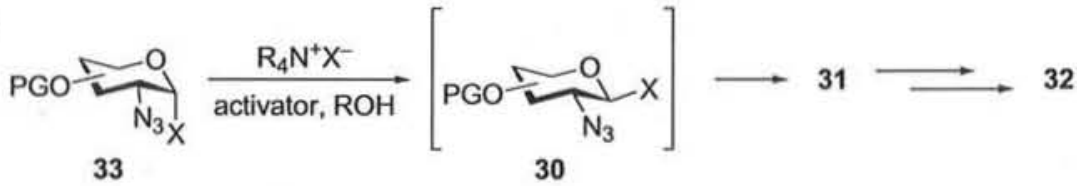

Scheme 16.9 Preparation of O-glycosides of 2-amino-2-deoxysugars. (A) Use of N-acylprotected donors 27 results in 1,2-trans glycosylation due to neighboring group participation. (B) 1,2-cis glycosylation products 32 from $\beta$-glycosyl halides $30^{54,55}$ or (C) by in situ anomerization $^{56}$ of $\alpha$-glycosyl halides $33^{57}$

be transformed to the natural acetamido function either in two steps by reduction of the azide and subsequent acetylation or in one step by reductive acetylation using thioacetic acid. $^{63,64}$

A successful approach for the synthesis of $O$-glycopeptides is the assembly of preformed, more or less complex glycosyl amino acid building blocks by solid phase peptide synthesis (SPPS) ${ }^{60-62,65-67}$ Based on initial work of Ferrari ${ }^{68}$ and Paulsen, ${ }^{69}$ the azide method is extensively used for the preparation of such glycosyl amino acid building blocks. Especially the synthesis of complex glycosyl amino acids is challenging. Usually, glycosylation is performed with monosaccharides followed by attachment of further sugar residues because glycosylation reactions with oligosaccharide donors and serine or threonine acceptors often proceed with unpredictable stereochemistry. Nevertheless, oligosaccharides have been successfully used in many glycosylations as illustrated by the synthesis of glycosyl threonine building block 38 reported by Danishefsky and coworkers (Scheme 16.10). ${ }^{64}$

\subsection{Glycosyl Azides as Precursors for Glycosyl Amides}

Beside the $O$-linked glycoproteins, the more prevalent form of glycosylation of proteins is $N$-linked glycosylation. ${ }^{48.70 .71} \mathrm{~N}$-Glycoproteins are characterized by a $\beta$ - $N$-glycosidic linkage of the terminal $\mathrm{N}$-acetylglucosamine of the pentasaccharide core structure to the amide nitrogen of asparagine. The conventional synthetic strategy for the preparation of such glycosyl amides starts from glycosyl amines which are reacted with activated and 


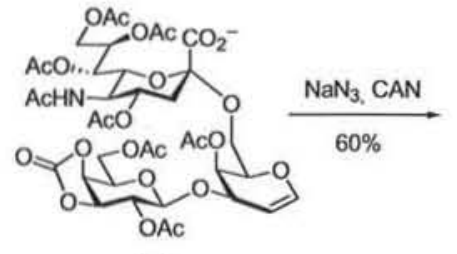

34
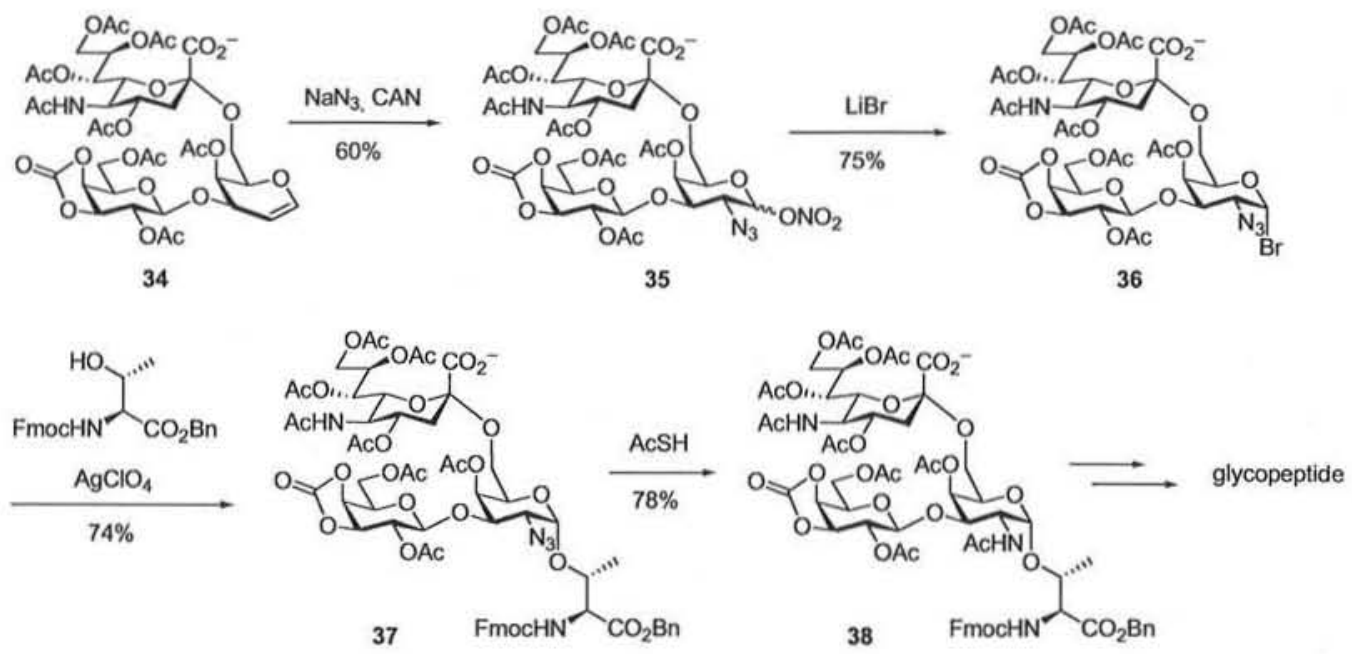

Scheme 16.10 Synthesis of glycosyl threonine building block 38 using the azide method. ${ }^{64}$ The 2-azido group is introduced by azidonitration of 34 followed by preparation of donor 36. Glycosylation using threonine as acceptor leads to 1,2-cis glycoside 37. After conversion of the azide group to an $\mathrm{N}$-acetyl group by reductive acetylation, 38 was used as building block in glycopeptide synthesis

suitably protected aspartic acid derivatives to form the amide linkage. ${ }^{60-62.65-67}$ Glycosyl amines are commonly prepared either by reduction of glycosyl azides (cf. Section 16.3) or by amination of unprotected reducing sugars with saturated aqueous ammonium bicarbonate. ${ }^{72}$ Recently, improved variants of the latter procedure employing microwave irradiation ${ }^{73,74}$ and ammonium carbamate, ${ }^{75.76}$ respectively, have been published. Drawbacks of this method are the instability of glycosyl amines and their propensity for dimerization and anomerization. Also, the preparation of $\alpha$-glycosyl amides is a synthetic challenge.

While the classical Staudinger reaction ${ }^{35}$ leads to iminophosphoranes which can be hydrolyzed to amines under aqueous conditions (Staudinger reduction, cf. Section 16.3), the addition of acyl donors under dry conditions results in amide formation. ${ }^{77.78}$ This procedure was repeatedly applied for the synthesis of glycosyl amides, thus circumventing the preparation of glycosyl amines. Initially, three-component reactions employing glycosyl azide, activated carboxyl derivative and phosphine were reported (Scheme 16.11). The reaction starts from the $\beta$ - (39) or $\alpha$-glycoside 45 with the formation of an iminophosphorane (40 and $\mathbf{4 2}$, respectively), which is then trapped by an acylating agent in the second step. The resulting acylaminophosphonium salt (43/46) yields the corresponding glycosyl amide (44/47) upon hydrolysis. The intermediate iminophosphorane can undergo anomerization via open-chain form $\mathbf{4 1}$ preferring $\beta$-configuration. The degree of isomerization is dependent on the efficiency of iminophosphorane trapping by the acylating agent. Differently activated carboxylic acids, such as carboxylic halides, ${ }^{79.80}$ anhydrides ${ }^{80.81}$ and carbodiimide-activated acids, ${ }^{82,83}$ have been employed as acylating agents. While $\beta$ glycosyl amides 44 can be obtained easily from $\beta$-glycosyl azides 39 , the stereospecific 


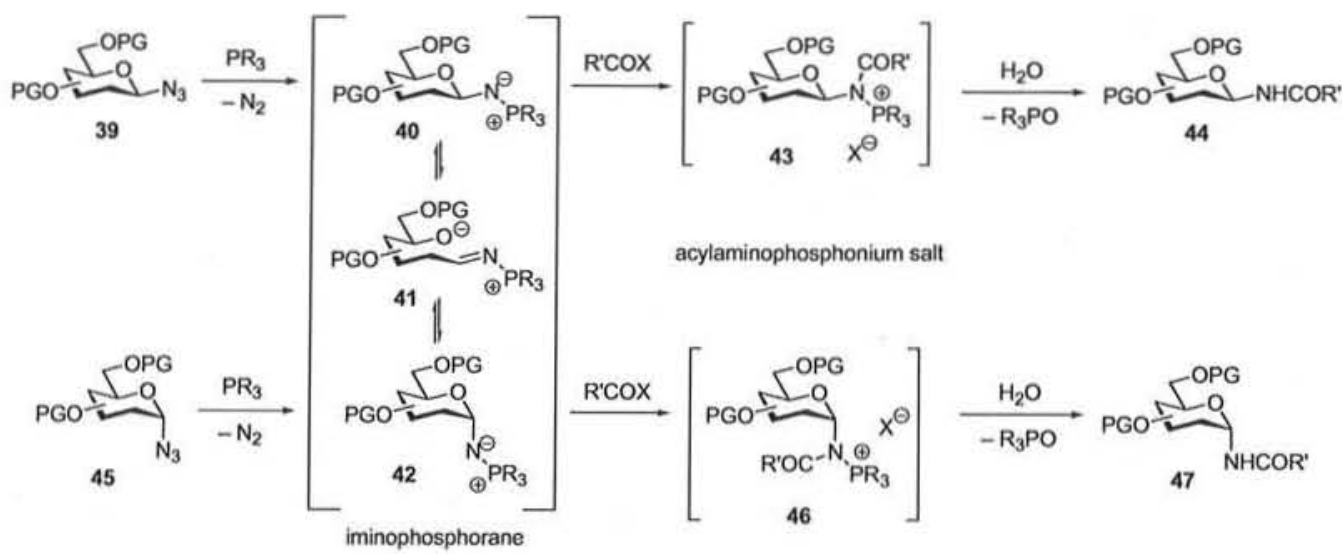

Scheme 16.11 Mechanism of the Staudinger reaction with glycosyl azides
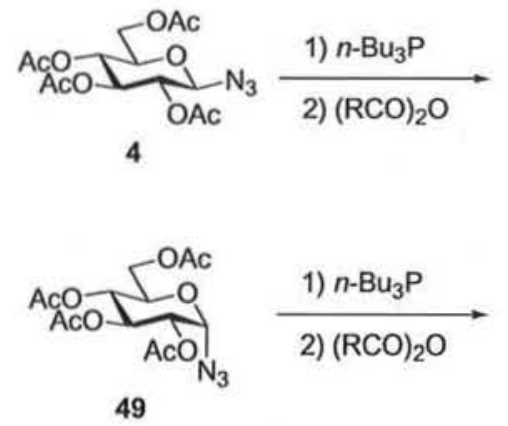

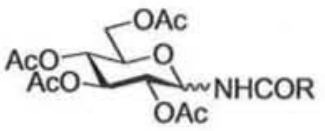

48
$\mathrm{R}=\mathrm{CH}_{3}: 72 \%$ ( $\beta$ only)
$\mathrm{R}=\mathrm{CF}_{3}: \quad 76 \%$ ( $\beta$ only $)$

$\mathrm{R}=\mathrm{CF}_{3} ; \quad 76 \%(\beta$ only $)$

48

$\mathrm{R}=\mathrm{CH}_{3}: 72 \%(\beta$ only $)$

$R=C F_{3}: \quad 61 \%(\alpha / \beta=85: 15)$

Scheme 16.12 Three-component Staudinger-type reaction with $\beta$-glycosyl azide 4 stereoselectively leads to the $\beta$-glycosyl amides 48. $\alpha$-Glycosyl amides can only be obtained from $\alpha$-glycosyl azide 49 with strong acylating agents to prevent complete anomerization of the intermediate iminophosphorane ${ }^{80}$

synthesis of $\alpha$-glycosyl amides 47 starting from $\alpha$-glycosyl azides $\mathbf{4 5}$ is only possible with strong acylating agents which trap the intermediate iminophosphorane 42 before anomerization can take place. ${ }^{80}$ Representative examples for the three-component Staudinger reaction are shown in Scheme 16.12. Rarely, the Staudinger reaction with reactive alkylphosphines and free carboxylic acids has been reported. ${ }^{84,85}$ In this case, amide-bond formation is assumed to proceed in a concerted reaction without generation of an iminophosphorane intermediate.

Recently, the synthesis of glycosyl amides has also been achieved employing the traceless two-component Staudinger ligation ${ }^{9.86,87}$ developed in the laboratories of Bertozzi ${ }^{88}$ and Raines ${ }^{89.90}$ (Scheme 16.13). Starting from glycosyl azides $\mathbf{5 0}$ and $\mathbf{5 5}$, respectively, the initially formed iminophosphorane 52/57 reacts with an intramolecular (thio)ester group to form the acylaminophosphonium salt $\mathbf{5 3 / 5 8}$ from which the phosphine moiety is removed by hydrolysis with water. Using benzyl protected $\alpha$-glycosyl azides such as $\mathbf{5 0}$ 
A

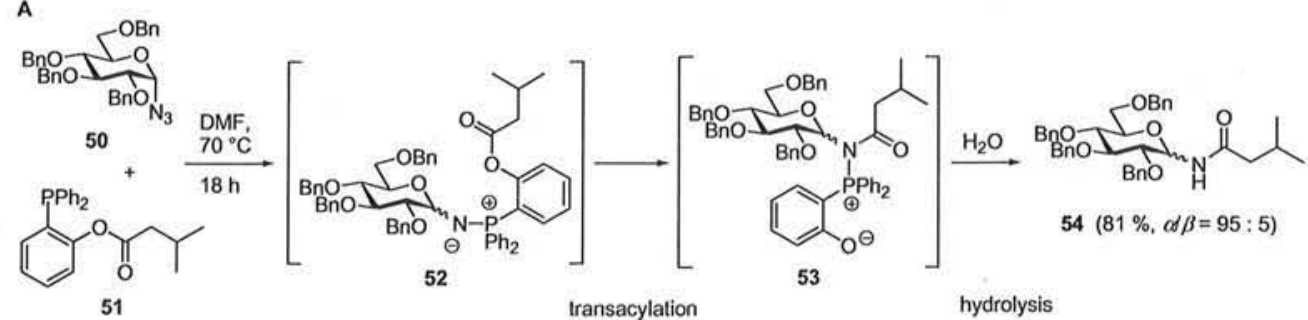

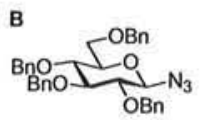

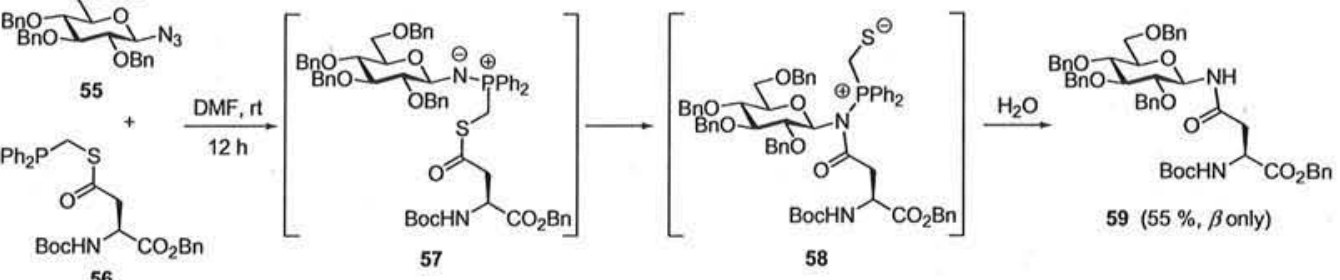

56

Scheme 16.13 Two-component traceless Staudinger ligations using phosphine-derivatized ester $51(A)^{9}$ or thioester $56(B)^{87}$

and stable phosphine $\mathbf{5 1}$ or similar esters in polar aprotic solvents such as DMF, the reaction proceeded stereo conservatively to yield predominantly $\alpha$-glycosyl amides (Scheme 16.13A). ${ }^{9}$ The use of acetyl protected $\alpha$-glycosyl azides, however, resulted only in $\beta$ glycosyl amides due to isomerization of the less reactive iminophosphorane.

All methods described above have been used for the preparation of the $\beta$-glycosyl amide linkage between $\mathrm{N}$-acetylglucosamine and the side chain of asparagine in both three-component reactions using free ${ }^{84,85}$ or activated ${ }^{82,83}$ carboxylic acids and twocomponent reactions as shown in Scheme 16.13.9.87 The obtained protected glycosyl amino acids can be used as building blocks in SPPS of $N$-linked glycopeptides. ${ }^{91,92}$ It was also shown that deprotected sugars can be attached to amino acids and whole peptides using the three-component reaction..$^{92}$ Beside Staudinger-type reactions, another route towards the synthesis of glycosyl amides is the reaction of glycosyl azides with thiocarboxylic acids. ${ }^{93}$

\subsection{Synthesis of Glycoconjugates via Azide-Alkyne [3+2] Cycloaddition}

Although the azide-alkyne [3+2] cycloaddition ${ }^{94}$ (cf. Chapter 9) is known in carbohydrate chemistry for more than 50 years, ${ }^{95}$ its application for the preparation of glycoconjugates became particularly attractive with the development of the copper(I)-catalyzed variant by Meldal ${ }^{96}$ and Sharpless. ${ }^{97}$ The copper(I)-catalyzed azide-alkyne cycloaddition $(\mathrm{CuAAC})^{98,99}$ enables the regioselective formation of 1,4-disubstituted 1,2,3-triazoles under very mild conditions even in a biological context. However, the cellular toxicity of the copper catalyst precludes applications wherein cells must remain viable. Therefore, as an alternative 


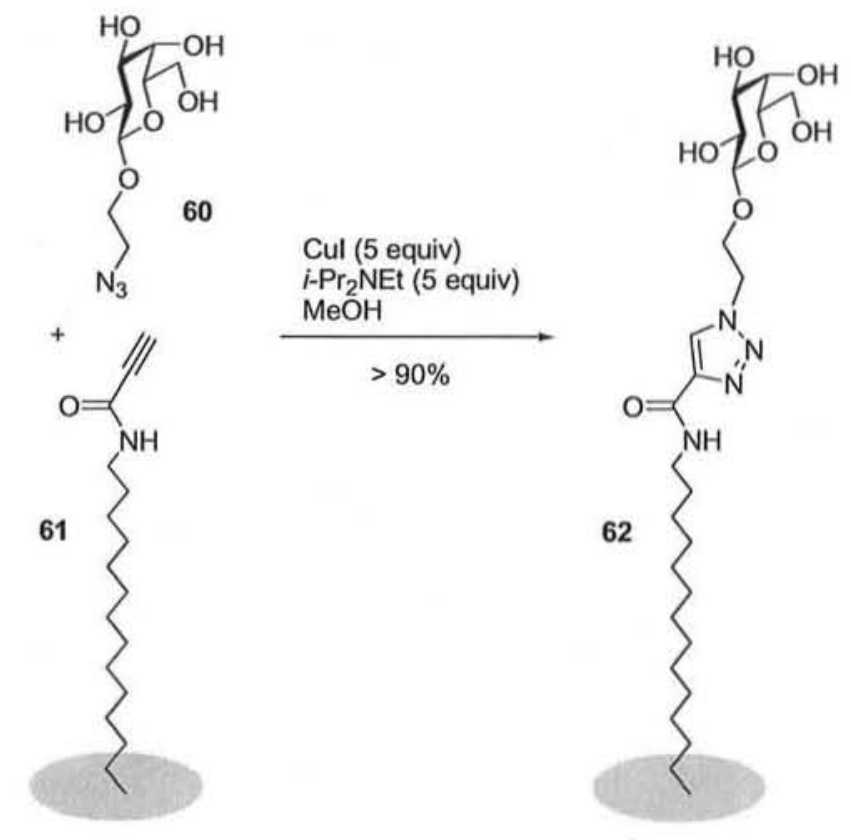

Scheme 16.14 Coupling of azide-substituted galactoside 60 to alkyne-modified $C_{14}$ hydrocarbon 61 noncovalently bound to the microtiter well surface ${ }^{108}$

to CuAAC, strain-promoted azide-alkyne [3+2] cycloadditions have been developed that proceed at room temperature without the need for a catalyst. ${ }^{100,101}$ These reactions are discussed in the next section dealing with metabolic oligosaccharide engineering. Another example of metal-free triazole formation by a tandem [3+2] cycloaddition-retro-DielsAlder reaction has been developed by van Berkel $e t$ al. although no carbohydrate-related application was reported. ${ }^{102}$

CuAAC reactions have been extensively applied in carbohydrate chemistry including the synthesis of simple glycoside and oligosaccharide mimetics, glyco-macrocycles, glycoconjugates, glycoclusters, and for the attachment of carbohydrates to surfaces. The field has been thoroughly reviewed ${ }^{98.103-107}$ and, therefore, we will focus on a few selected examples which are of special interest for glycobiology.

One of the first applications of CuAAC in carbohydrate chemistry was - beside the one in the seminal paper of $\mathrm{Meldal}^{96}$ - the immobilization of azide-substituted sugars on microtiter plates (Scheme 16.14). ${ }^{108}$ The surface-bound sugars such as 62 were screened with various lectins and could be elongated by glycosyltransferase-catalyzed fucosylation. The technique was later on improved by incorporation of a cleavable disulfide bond in the linker allowing mass spectrometric characterization of the carbohydrate array. ${ }^{109}$

Neoglycopeptides and -proteins ${ }^{110}$ differ from naturally occurring structures by replacement of the natural carbohydrate-peptide linkage with a non-natural one. This not only allows studying the influence of distinct structural elements on biological activity, but has many practical applications as well. Use of chemoselective ligation reactions such as 


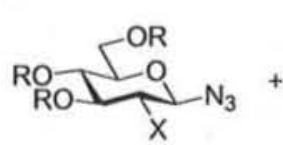

63

$\mathrm{R}=\mathrm{Ac}, \mathrm{Bn}, \mathrm{Bz}$ $X=O R, N H A C$<smiles>C#CCC(NC=O)C(=O)OC</smiles>

64

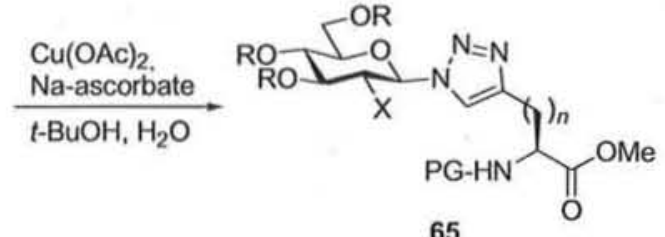

65 $n=1,2,3$

Scheme 16.15 Application of CUAAC for the preparation of triazole-linked glycosyl amino acids $65^{111}$
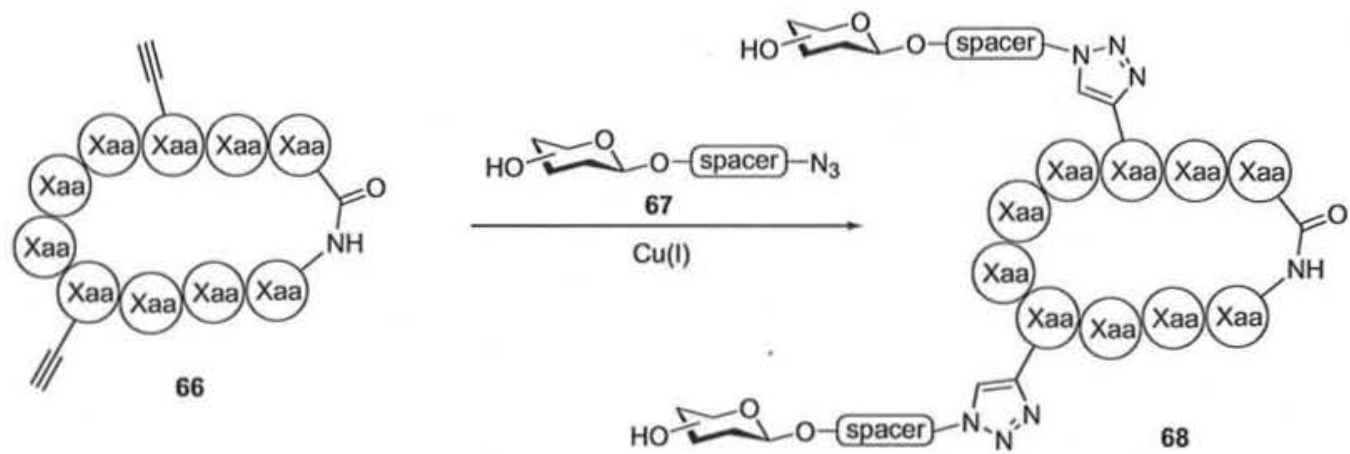

Scheme 16.16 Preparation of tyrocidine derivatives 68 by CUAAC of propargylglycinecontaining cyclic peptides 66 and azido-functionalized sugars $67^{113}$

CuAAC makes glycoconjugates accessible to a broader community. Furthermore, the non-natural linkage often is more stable (both chemically and with respect to enzymatic degradation) which can lead to an increased half life of a glycoconjugate within a biological system. Scheme 16.15 depicts the synthesis of triazole-linked glycosyl amino acids 65 starting from glycosyl azides 63 and different alkyne-containing amino acids 64 which can be used as building blocks in peptide synthesis. ${ }^{111,112}$

Lin and Walsh applied CuAAC for the attachment of 21 different azido-functionalized monosaccharides 67 to 13 derivatives $\mathbf{6 6}$ of the cyclic decapeptide tyrocidine containing one to three propargylglycine residues at positions $3-8$ (Scheme 16.16). ${ }^{113}$ Head-to-tail cyclization of the peptides was accomplished using a thioesterase domain from tyrocidine synthetase. Antibacterial and hemolytic assays showed that the two best glycopeptide mimetics had a 6 -fold better therapeutic index than the natural tyrocidine. CuAAC has further been used to attach carbohydrates to whole virus particles ${ }^{114,115}$ and DNA. ${ }^{116}$

More challenging is the modification of bacterially expressed proteins by site-specific attachment of carbohydrates. Crucial step is the introduction of a chemical tag, which can be chemoselectively modified, into the protein. It has been shown that alkyne- and azido-modified amino acids, such as 2-amino-5-hexynoic acid (homopropargylglycine, $\mathrm{Hpg}$ ), ${ }^{117}$ 4-azidohomoalanine (Aha), ${ }^{118.119}$ and with less efficiency also 3-azidoalanine, 5 -azidonorvaline, and 6-azidonorleucine, ${ }^{120}$ act as methionine surrogates that are acti- 
vated by the methionyl-tRNA synthetase of $E$. coli and replace methionine in proteins expressed in methionine-depleted bacterial cultures. This, together with other methods for the incorporation of non-canonical amino acids into proteins, ${ }^{121-123}$ offers the possibility to use azide-alkyne cycloaddition (and also Staudinger ligation ${ }^{124-126}$ ) not only for protein labeling within cells or on cell surfaces ${ }^{119.120}$ but also for the preparation of neoglycoproteins.

Davis and coworkers expanded the diversity of chemical protein modification by a combination of this CuAAC-based labeling and disulfide bond formation via genetically engineered cysteine (Cys) residues. ${ }^{127} \mathrm{Aha}$ and $\mathrm{Hpg}$, respectively, were introduced into engineered proteins by the auxotrophy-based residue-specific method. Subsequent CuAAC reactions with alkyne- and azide-substituted carbohydrates, respectively, resulted in homogeneous protein glycoconjugates. As second modification reaction, conjugation of Cys residues with substituted methanethiosulfonates was chosen. Applying these two orthogonal protein modification reactions, derivatives of the LacZ reporter enzyme carrying the tetrasaccharide sialyl Lewis $\mathrm{X}$ and a sulfotyrosine mimic were created that allowed detection of mammalian brain inflammation.

Recently, Merkel et al. reported efficient $\mathrm{N}$-terminal glycoconjugation of proteins by the $\mathrm{N}$-end rule. ${ }^{128}$ Bulky amino acids at the second and third sequence position of the barnase inhibitor barstar efficiently prevent excision of $\mathrm{N}$-terminal methionine analogue Aha introduced by the auxotrophy-based residue-specific method. The created azide tag at the protein's $\mathrm{N}$-terminus was subsequently conjugated to propargyl glycosides of $\mathrm{N}$ acetylglucosamine and $N, N^{\prime}$-diacetylchitobiose, respectively, by CuAAC. The obtained glycoprotein mimetics show binding affinity to the lectin wheat germ agglutinin whereas the natural activity of barstar is conserved.

Lectins are carbohydrate-binding proteins other than immunoglobulins without enzymatic activity towards the recognized sugars. ${ }^{129-131}$ Carbohydrate-lectin interactions are involved in numerous intra- and intercellular events during development, inflammation, immune response and cancer metastasis. ${ }^{132-136}$ Multivalency appears to play an important role in lectin-mediated interactions, ${ }^{137-140}$ and many lectins are found to recognize individual carbohydrate epitopes only with low affinity. Preparation of carbohydrate clusters, therefore, is a common strategy to obtain high-affinity lectin ligands. ${ }^{141-144}$ Because of its robustness, CuAAC is excellently suited for the simultaneous attachment of several carbohydrate epitopes to a scaffold. Initially, Santoyo-Gonzáles and coworkers prepared different multivalent mannose clusters starting from propargyl mannosides and azidecontaining scaffolds. ${ }^{145}$ This strategy as well as the opposite approach based on azidecontaining carbohydrates and alkyne-bearing scaffolds have been used intensively for the preparation of glycoclusters. ${ }^{98,103-107}$ Glycosyl azides are easily produced, however, the direct attachment of a triazole to the sugar may interfere with the recognition of the carbohydrate by the protein and, therefore, linkers of varying length have been introduced between the sugar and the triazole moiety. It would be far beyond the scope of this chapter to mention all applications. Exemplarily, the asymmetrical, bifunctional dendrimer 69 containing 16 mannose units and two coumarin chromophores ${ }^{146}$ and poly(methacrylate)based glycopolymer $\mathbf{7 0}^{147}$ are depicted in Scheme 16.17.

Although organic azides are stable against most reaction conditions, compounds containing multiple azide residues (like multivalent scaffolds) are potentially explosive. Therefore, several one-pot procedures to generate azides in situ followed by CuAAC have 
A

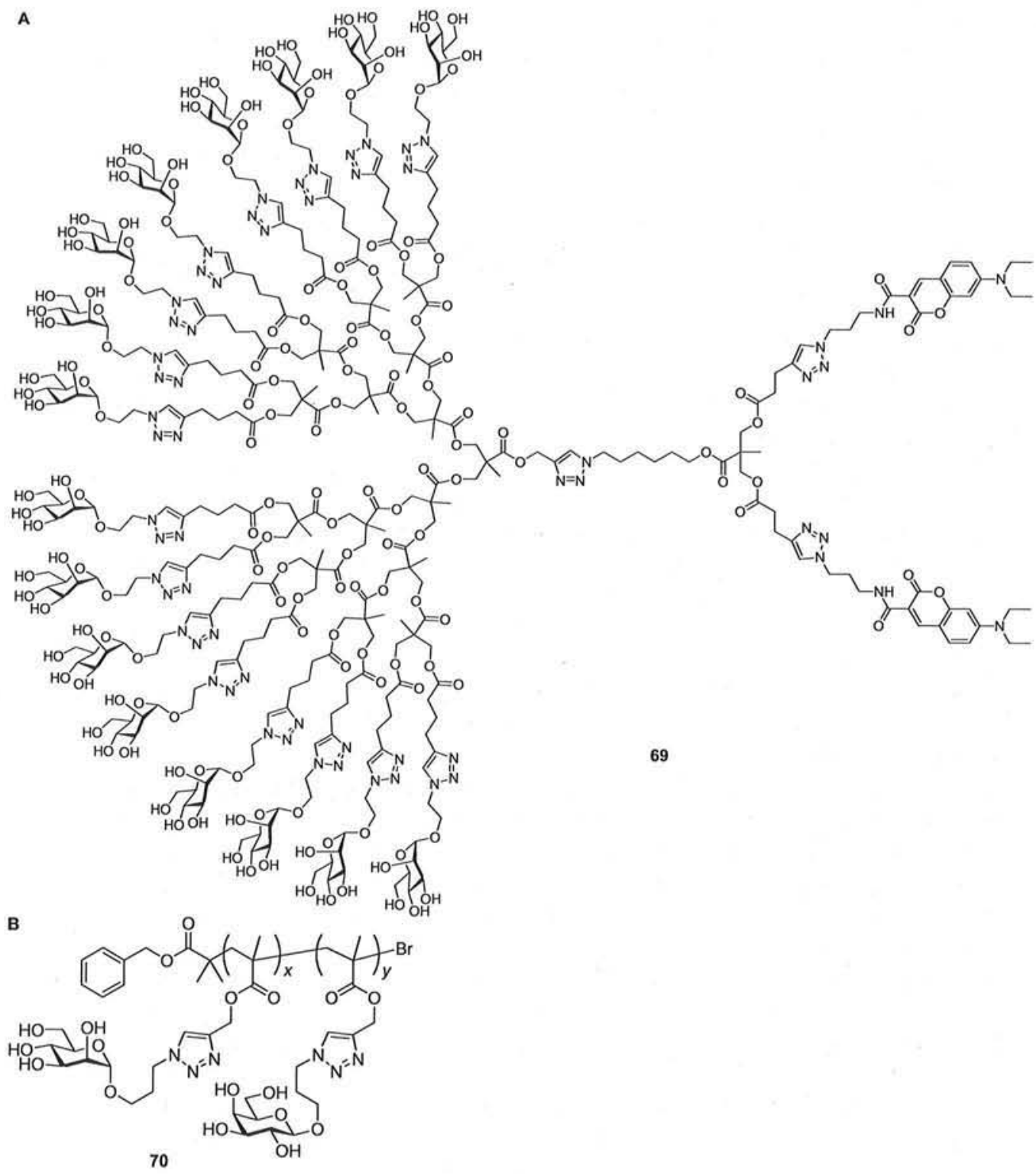

Scheme 16.17 (A) Asymmetrical, bifunctional dendrimer 69 containing 16 mannose units and two coumarin chromophores ${ }^{146}$ and $(B)$ poly(methacrylate)-based glycopolymer $70^{147}$ prepared by CUAAC and used for lectin binding studies with concanavalin $A$

been reported. ${ }^{148-154}$ While the azides in most of these procedures are introduced by a nucleophilic substitution of a leaving group in allyl, benzyl, glycosyl, or similar position, ${ }^{148-152}$ aliphatic ${ }^{154}$ and aromatic ${ }^{153}$ amino groups may also serve as precursors. We reported, for example a one-pot procedure for diazo transfer and subsequent CuAAC which allows the preparation of multivalent structures starting from commercially avail- 


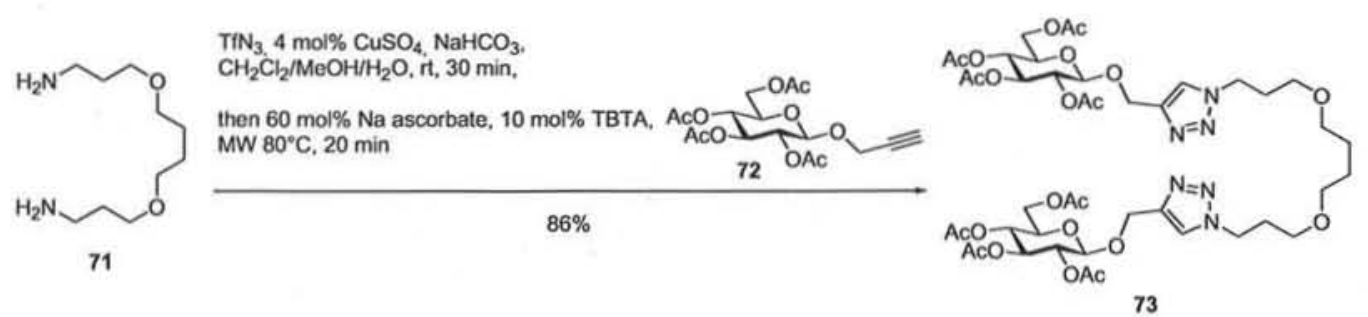

Scheme 16.18 Sequential one-pot procedure for diazo transfer and CuAAC. ${ }^{154}$ First, diamine 71 is transformed to the corresponding diazide by Cu(II)-catalyzed diazo transfer. After completion, $C u(I)$ required for subsequent CUAAC with 72 is generated by addition of reducing agent $\mathrm{Na}$ ascorbate. $\mathrm{MW}=$ microwave; $T B T A=$ tris (benzy/triazolylmethyl)amine

able amine scaffolds without need for isolation of the azide-containing intermediates. ${ }^{154}$ As an example, divalent glycoconjugate $\mathbf{7 3}$ was synthesized from diamine $\mathbf{7 1}$ and propargyl glycoside 72 as shown in Scheme 16.18.

Azides can also undergo $[3+2]$ cycloaddition reactions with nitriles giving access to 1,5-disubstituted tetrazoles. Intermolecular reactions, however, require electron deficient nitriles and very forcing conditions to occur with sufficiently high reaction rates. ${ }^{155-157}$ High yields have been reported for the reaction of sulfonyl and acyl cyanides with unhindered aliphatic azides by neat, thermal fusion. ${ }^{158.159}$ Intramolecular $[3+2]$ cycloaddition reactions of organic azides to nitriles occur more readily. ${ }^{160-164}$ Still, they require high reaction temperatures and yields are with few exceptions ${ }^{165}$ not satisfactory. When precisely positioned on a rigid carbohydrate scaffold, however, azides can undergo cycloaddition reactions with nitriles under exceptionally mild conditions. Thus, 3-azido-1,2$O$-cyanoethylidene-3-deoxy-allopyranose was shown to form a tetrazole embedded in a bridged tetracyclic ring system even at room temperature. ${ }^{166}$

\subsection{Metabolic Oligosaccharide Engineering}

Glycosylation of proteins is an important co- and posttranslational event that has been estimated to occur on more than $50 \%$ of eukaryotic proteins. ${ }^{167}$ The glycan chains of cell-surface glycoproteins are involved in numerous recognition processes such as cell adhesion and attachment of bacteria or viruses. Inside cells, glycans direct protein trafficking and they modulate structure and activity of proteins. ${ }^{132-136} \mathrm{Hence}$, in vivo monitoring of glycosylation processes is of utmost interest. ${ }^{168}$ While fluorescent fusion proteins and other genetically encoded tags provide a means for labeling specific proteins in live cells, analogous techniques are not available for secondary gene products including glycans. Metabolic oligosaccharide engineering offers the possibility to introduce carbohydrates with unnatural structural elements into the glycans without genetic manipulation making use of the cell's biosynthetic machinery. ${ }^{169}$ If suitable chemical reporter groups are introduced, subsequent addition of an exogenously delivered detectable probe allows for tagging of the glycans by a chemoselective ligation reaction. Examples for such reporter groups include ketones ${ }^{170,171}$ and thiols. ${ }^{172}$ However, the azido group is much more 

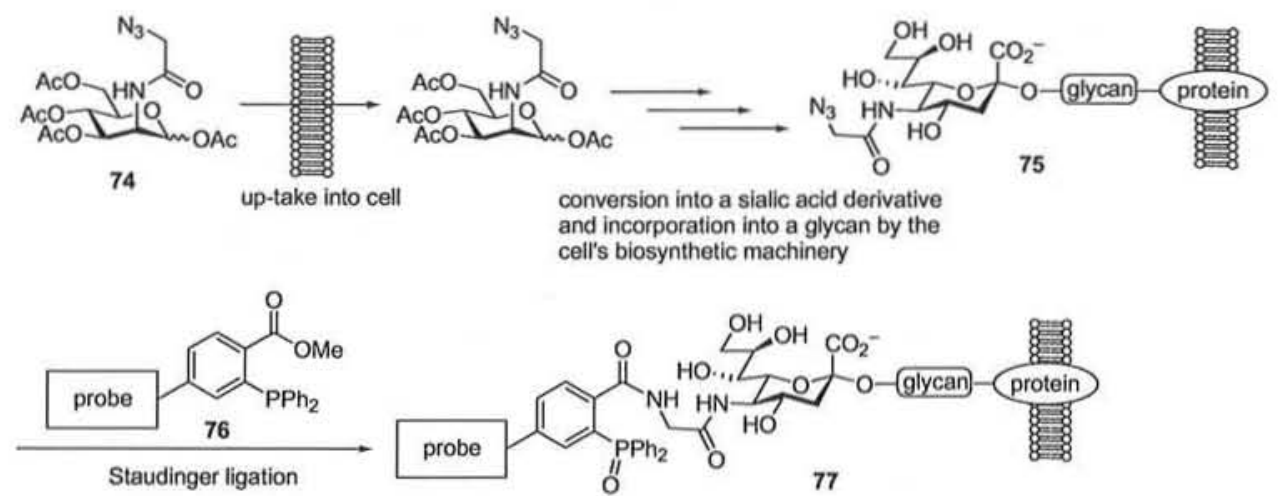

Scheme 16.19 Metabolic oligosaccharide engineering: peracetylated ManNAz 74 is taken up by mammalian cells and converted into an azide-containing sialic acid derivative which is incorporated into sialic acid-bearing glycans 75 . In the next step, a detectable probe 76 can be attached to 75 via Staudinger ligation ${ }^{124,173}$

suited for this approach because azides can take part in two important bioorthogonal ligation reactions, Staudinger ligation ${ }^{124}(\mathrm{cf}$. Section 16.5) and azide-alkyne [3+2] cycloaddition (cf. Section 16.6 and Chapter 9).

Azide derivatization of monosaccharides represents a subtle structural change that is accepted by several metabolic pathways. Thus, azide derivatives of $N$-acetylmannosamine (i.e. $N$-(azidoacetyl)mannosamine, ManNAz), $N$-acetylgalactosamine (i.e. $N$-(azidoacetyl) galactosamine, GalNAz), $N$-acetylglucosamine (i.e. $N$-(azidoacetyl)glucosamine, GlcNAz), and L-fucose (i.e. 6-azido-L-fucose) have been explored. ${ }^{168.169}$ Initially, ManNAz was employed to tag sialylated cell surface glycans of mammalian cells in vitro (Scheme 16.19) ${ }^{124.173}$ Cells are grown in the presence of peracetylated ManNAz 74 which can be taken up by the cells more easily than ManNAz. After de- $O$-acetylation by cellular esterases, resulting ManNAz is metabolized similarly to its native counterpart $N$-acetylmannosamine and integrated into cellular glycans. Finally, the azide-labeled glycans are reacted with a detectable probe by Staudinger ligation. GalNAz can be metabolically introduced at the core position of mucin-type $O$-linked glycoproteins. ${ }^{174}$ Thus, a selective labeling of mucin-type glycoproteins is possible. Both, the metabolic labeling of sialylated glycans with ManNAz ${ }^{175}$ and labeling of mucin-type $O$-glycoproteins with $\mathrm{GalNAz}^{176} \mathrm{can}$ be carried out in vivo. Analogously, GlcNAz has been used for the labeling of $O$-GlcNAc glycosylated proteins. ${ }^{177}$ Recently, cells were labeled simultaneously with an azide- and a ketone-containing sugar. ${ }^{178}$ Using orthogonal ligation reactions, glycans bearing these sugar residues can be visualized in parallel on the same cells.

In the cases mentioned so far, fluorescence labeling has been achieved by a two-step procedure. First, a biotin label ${ }^{124}$ or FLAG tag (octapeptide Asp-Tyr-Lys-Asp-Asp-AspAsp-Lys) $)^{173,174,177}$ is covalently attached to the azide-containing glycan by Staudinger ligation at high concentration. In a second step, a fluorescently labeled receptor (avidin and anti-FLAG antibody, respectively) is added at lower concentration. To avoid the problem of high background fluorescence caused by the application of fluorescent dyes, 


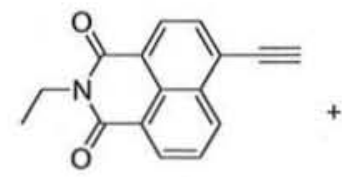

78

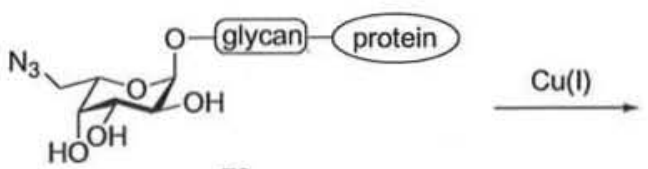

79

non-fluorescent<smiles>CCN1C(=O)c2cccc3c(-c4cn(CC5OC(O)C(O)C(O)C5O)nn4)ccc(c23)C1=O</smiles>

Scheme 16.20 Generation of fluorescent triazole 80 by CuAAC of fluorogenic ethynylnaphthalimide $\mathbf{7 8}$ and azide-labeled glycoproteins 79 applicable for intracellular localization of fucosylated glycoconjugates ${ }^{179}$

Wong and coworkers developed a one-step labeling method based on CuAAC ligation using fluorogenic dyes (Scheme 16.20). ${ }^{179}$ 6-Azido-L-fucose was applied for tagging of fucosylated proteins by metabolic oligosaccharide engineering. Reaction of alkyne-substituted naphthalimide $\mathbf{7 8}$ and azide-modified glycoprotein $\mathbf{7 9}$ results in formation of fluorescent triazole $\mathbf{8 0}$. Since $\mathbf{7 8}$ is not fluorescent, it can be applied at high concentrations without producing a background signal. The method was used for cell surface glycoprotein analysis and intracellular localization of fucosylated glycoconjugates by using fluorescence microscopy.

Other examples for the application of CuAAC for labeling and visualization of glycoproteins in cells have been published by the research groups of Bertozzi ${ }^{180}$ and Wong. ${ }^{181}$ The main advantage of CuAAC over Staudinger ligation is its much faster reaction kinetics. However, the use of CuAAC for applications in vivo is limited due to the cellular toxicity of copper ions. This led to the development of copper-free variants of this cycloaddition. Based on observations made by Wittig who described the exothermic cycloaddition of cyclooctyne with phenyl azide, ${ }^{182}$ Bertozzi and coworkers reported the copper-free, strain-promoted cycloaddition between azides and substituted cyclooctyne 81 for covalent modification of biomolecules in living systems (Scheme 16.21). ${ }^{100}$ The reaction rates were lower than those of CuAAC but comparable to those of Staudinger ligation. ${ }^{183}$ The validity of the approach was demonstrated by functionalization of modified Jurkat cells with a biotin derivative of $\mathbf{8 1} .^{100}$ Reaction rates of the strain-promoted azide-alkyne cycloaddition could be dramatically improved by introduction of electronwithdrawing fluorine substituents in $\alpha$ position of the triple bond (Scheme 16.21, 82-84) with the difluorinated cyclooctyne (DIFO) derivatives 83 and 84 possessing comparable kinetics to those of CuAAC. ${ }^{183-185}$ Similar reaction rates were observed with dibenzocyclooctyne derivative $\mathbf{8 5}$. $^{101}$ These reactions are not regioselective but proceed chemoselectively within minutes on live cells with no apparent toxicity. ${ }^{101.184,185}$ Latest application of DIFO derivative $\mathbf{8 3}$ is the in vivo imaging of membrane-associated glycans in live 
<smiles>[R]C(=O)c1ccc(COC2C#CCCCCC2)cc1</smiles>

81<smiles>[R]C(=O)c1ccc(CCC2(F)C#CCCCCC2)cc1</smiles>

82<smiles>[R]C(=O)COC1CCC#CC(F)(F)CC1</smiles>

83<smiles>[R]C(=O)CC1CCCCC#CC1(F)F</smiles>

84<smiles>[R]C(=O)OC1Cc2ccccc2C#Cc2ccccc21</smiles>

85

Scheme 16.21 Cyclooctyne derivatives for use in copper-free, strain-promoted azide-alkyne $[3+2]$ cycloadditions designed by Bertozzi $\left(81,{ }^{100} 82,{ }^{183} 83,{ }^{184} 84^{185}\right)$ and Boons $\left(85^{101}\right)$. The second-generation difluorinated derivative $\mathbf{8 4}$ is easier to synthesize than $\mathbf{8 3}$

developing zebrafish. ${ }^{186}$ Using two derivatives 83 with different fluorophores attached, it was possible to perform a spatiotemporal analysis of glycan expression and trafficking.

\section{References}

[1] A. Bertho, Ber. Dtsch. Chem. Ges. 1930, 63, 836-43.

[2] Z. Györgydeák, L. Szilágyi, H. Paulsen, J. Carbohydr. Chem. 1993, 12, 139-63.

[3] M. Hayashi, H. Kawabata, in Recent Devel. Carbohydrate Res., Vol. I (ed.: S.G. Pandalai), Transworld Research Network, Trivandrum, 2003, pp. 195-208.

[4] Z. Györgydeák, J. Thiem, Adv. Carbohydr. Chem. Biochem. 2006, 60, 103-82.

[5] W. Pfleiderer, E. Bühler, Chem. Ber. 1966, 99, 3022-39.

[6] F.D. Tropper, F.O. Andersson, S. Braun, R. Roy, Synthesis 1992, 618-20.

[7] R. Kumar, P. Tiwari, P.R. Maulik, A.K. Misra, Eur. J. Org. Chem 2006, 74-9.

[8] H. Paulsen, Z. Györgydeák, M. Friedmann, Chem. Ber. 1974, 107, 1568-78.

[9] A. Bianchi, A. Bernardi, J. Org. Chem. 2006, 71, 4565-77.

[10] F. Sicherl, V. Wittmann, Angew. Chem., Int. Ed. 2005, 44, 2096-9.

[11] C. Vogel, P. Gries, J. Carbohydr. Chem. 1994, 13, 37-46.

[12] A. Fürst, P.A. Plattner, in Abstracts of Papers, 12th International Congress of Pure and Applied Chemistry, New York, 1951, p. 409.

[13] S. Arndt, L.C. Hsieh-Wilson, Org. Lett. 2003, 5, 4179-82.

[14] R.U. Lemieux, R.M. Ratcliffe, Can. J. Chem. 1979, 57, 1244-51.

[15] A.F.G. Bongat, A.V. Demchenko, Carbohydr. Res. 2007, 342, 374-406.

[16] G. Grundler, R.R. Schmidt, Liebigs Ann. Chem. 1984, 1826-47.

[17] S.A. Svarovsky, J.J. Barchi, Jr., Carbohydr. Res. 2003, 338, 1925-35.

[18] H. Paulsen, W. Rauwald, U. Weichert, Liebigs Ann. Chem. 1988, 75-86.

[19] J. Hansson, P.J. Garegg, S. Oscarson, J. Org. Chem. 2001, 66, 6234-43.

[20] J.D.C. Codée, R.E.J.N. Litjens, R. den Heeten, et al., Org. Lett. 2003, 5, 1519-22.

[21] N.V. Bovin, S.E. Zurabyan, A.Y. Khorlin, Carbohydr. Res. 1981, 98, 25-35.

[22] F. Santoyo-González, F.G. Calvo-Flores, P. García-Mendoza, et al., J. Org. Chem. 1993, 58, 6122-5.

[23] S. Czernecki, E. Ayadi, D. Randriamandimby, J. Org. Chem. 1994, 59, 8256-60.

[24] C.J. Cavender, V.J. Shiner, J. Org. Chem. 1972, 37, 3567-9.

[25] A. Vasella, C. Witzig, J.-L. Chiara, M. Martin-Lomas, Helv. Chim. Acta 1991, 74, 2073-7.

[26] P.B. Alper, S.-C. Hung, C.-H. Wong, Tetrahedron Lett. 1996, 37, 6029-32.

[27] P.T. Nyffeler, C.-H. Liang, K.M. Koeller, C.-H. Wong, J. Am. Chem. Soc. 2002, 124, 10773-8.

[28] O. Gavard, Y. Hersant, J. Alais, et al., Eur. J. Org. Chem. 2003, 3603-20. 
[29] Michael F. Haller, G.-J. Boons, Eur. J. Org. Chem. 2002, 2033-8.

[30] H.A. Orgueira, A. Bartolozzi, P. Schell, et al., Chem. Eur. J. 2003, 9, 140-69.

[31] S. Iyer, S. Rele, G. Grasa, S. Nolan, E.L. Chaikof, Chem. Commun. 2003, 1518-19.

[32] N. Laurent, D. Lafont, P. Boullanger, J.M. Mallet, Carbohydr. Res. 2005, 340, 1885-92.

[33] S. Bräse, C. Gil, K. Knepper, V. Zimmermann, Angew. Chem., Int. Ed. 2005, 44, 5188240.

[34] E.F.V. Scriven, K. Turnbull, Chem. Rev. 1988, 88, 297-368.

[35] H. Staudinger, J. Meyer, Helv. Chim. Acta 1919, 2, 635-46.

[36] X. Ariza, F. Urpi, J. Vilarrasa, Tetrahedron Lett. 1999, 40, 7515-17.

[37] X. Ariza, F. Urpi, C. Viladomat, J. Vilarrasa, Tetrahedron Lett. 1998, 39, 9101-2.

[38] J.G. Silva, I. Carvalho, Curr. Med. Chem. 2007, 14, 1101-19.

[39] D.S. Pilch, M. Kaul, C.M. Barbieri, Top. Curr. Chem. 2005, 253, 179-204.

[40] Q. Vicens, E. Westhof, ChemBioChem 2003, 4, 1018-23.

[41] M. Hainrichson, I. Nudelman, T. Baasov, Org. Biomol. Chem. 2008, 6, 227-39.

[42] Y. Ding, E.E. Swayze, S.A. Hofstadler, R.H. Griffey, Tetrahedron Lett. 2000, 41, 4049-52.

[43] M. Fridman, V. Belakhov, S. Yaron, T. Baasov, Org. Lett. 2003, 5, 3575-8.

[44] P.B. Alper, M. Hendrix, P. Sears, C.-H. Wong, J. Am. Chem. Soc. 1998, 120, 1965-78.

[45] W.A. Greenberg, E.S. Priestley, P.S. Sears, et al., J. Am. Chem. Soc. 1999, 121, 652741.

[46] J. Li, H.-N. Chen, H. Chang, J. Wang, C.-W.T. Chang, Org. Lett. 2005, 7, 3061-4.

[47] J. Li, F.-I. Chiang, H.-N. Chen, C.-W.T. Chang, J. Org. Chem. 2007, 72, 4055-66.

[48] V. Wittmann, in Glycoscience: Chemistry and Chemical Biology, 2 ed. (eds.: B. Fraser-Reid, K. Tatsuta, J. Thiem), Springer-Verlag, Berlin, 2008, pp. 1735-70.

[49] H.C. Hang, C.R. Bertozzi, Bioorg. Med. Chem. 2005, 13, 5021-34.

[50] P. Van den Steen, P.M. Rudd, R.A. Dwek, G. Opdenakker, Crit. Rev. Biochem. Mol. Biol. 1998, 33, 151-208.

[51] J.R. Bishop, M. Schuksz, J.D. Esko, Nature 2007, 446, 1030-7.

[52] J. Banoub, P. Boullanger, D. Lafont, Chem. Rev. 1992, 92, 1167-95.

[53] J. Debenham, R. Rodebaugh, B. Fraser-Reid, Liebigs Ann./Recueil 1997, 791-802.

[54] H. Paulsen, W. Stenzel, Chem. Ber. 1978, 111, 2334-47.

[55] H. Paulsen, C. Kolar, W. Stenzel, Chem. Ber. 1978, 111, 2358-69.

[56] R.U. Lemieux, K.B. Hendriks, R.V. Stick, K. James, J. Am. Chem. Soc. 1975, 97, 4056-62.

[57] H. Paulsen, O. Lockhoff, Tetrahedron Lett. 1978, 4027-30.

[58] H. Paulsen, Angew. Chem., Int. Ed. Engl. 1982, 21, 155-73.

[59] R.R. Schmidt, Angew. Chem., Int. Ed. Engl. 1986, 25, 212-35.

[60] H. Herzner, T. Reipen, M. Schultz, H. Kunz, Chem. Rev. 2000, 100, 4495-538.

[61] M.R. Pratt, C.R. Bertozzi, Chem. Soc. Rev. 2005, 34, 58-68.

[62] C. Haase, O. Seitz, Top. Curr. Chem. 2007, 267, 1-36.

[63] T. Rosen, I.M. Lico, D.T.W. Chu, J. Org. Chem. 1988, 53, 1580-2.

[64] J.B. Schwarz, S.D. Kuduk, X.-T. Chen, et al., J. Am. Chem. Soc. 1999, 121, 2662-73.

[65] B.G. Davis, Chem. Rev. 2002, 102, 579-601.

[66] T. Buskas, S. Ingale, G.-J. Boons, Glycobiology 2006, 16, 113R-136R.

[67] Glycopeptides and Glycoproteins: Synthesis, Structure, and Application (Topics in Current Chemistry, vol. 267) (ed.: V. Wittmann), Springer-Verlag, Berlin, 2007.

[68] B. Ferrari, A.A. Paviat, Carbohydr. Res. 1980, 79, C1-C7.

[69] H. Paulsen, J.-P. Holck, Carbohydr. Res. 1982, 109, 89-107.

[70] L. Lehle, S. Strahl, W. Tanner, Angew. Chem., Int. Ed. 2006, 45, 6802-18.

[71] P.M. Rudd, R.A. Dwek, Crit. Rev. Biochem. Mol. Biol. 1997, 32, 1-100.

[72] L.M. Likhosherstov, O.S. Novikova, V.A. Derevitskaya, N.K. Kochetkov, Carbohydr. Res. 1986, 146, c1-c5.

[73] M. Bejugam, S.L. Flitsch, Org. Lett. 2004, 6, 4001-4.

[74] M.A. Brun, M.D. Disney, P.H. Seeberger, ChemBioChem 2006, 7, 421-4.

[75] C.P.R. Hackenberger, M.K. O'Reilly, B. Imperiali, J. Org. Chem. 2005, 70, 3574-8. 
[76] L.M. Likhosherstov, O.S. Novikova, V.N. Shibaev, Dokl. Chem. 2002, 383, 89-92.

[77] J. Garcia, F. Urpi, J. Vilarrasa, Tetrahedron Lett. 1984, 25, 4841-4.

[78] I. Bosch, A. González, F. Urpí, J. Vilarrasa, J. Org. Chem. 1996, 61, 5638-43.

[79] V. Maunier, P. Boullanger, D. Lafont, J. Carbohydr. Chem. 1997, 16, 231-5.

[80] L. Kovacs, E. Osz, V. Domokos, W. Holzer, Z. Gyorgydeak, Tetrahedron 2001, 57, 4609-21.

[81] J.J. García-López, F. Santoyo-González, A. Vargas-Berenguel, J.J. Giménez-Martínez, Chem. Eur. J. 1999, 5, 1775-84.

[82] J.P. Malkinson, R.A. Falconer, I. Toth, J. Org. Chem. 2000, 65, 5249-52.

[83] N. Rockendorf, T.K. Lindhorst, J. Org. Chem. 2004, 69, 4441-5.

[84] T. Inazu, K. Kobayashi, Synlett 1993, 869-70.

[85] M. Mizuno, I. Muramoto, K. Kobayashi, H. Yaginuma, T. Inazu, Synthesis 1999, 162-5.

[86] A. Bianchi, A. Bernardi, Tetrahedron Lett. 2004, 45, 2231-4.

[87] Y. He, R.J. Hinklin, J. Chang, L.L. Kiessling, Org. Lett. 2004, 6, 4479-82.

[88] E. Saxon, J.I. Armstrong, C.R. Bertozzi, Org. Lett. 2000, 2, 2141-3.

[89] B.L. Nilsson, L.L. Kiessling, R.T. Raines, Org. Lett. 2000, 2, 1939-41.

[90] B.L. Nilsson, L.L. Kiessling, R.T. Raines, Org. Lett. 2001, 3, 9-12.

[91] M. Mizuno, K. Haneda, R. Iguchi, et al., J. Am. Chem. Soc. 1999, 121, 284-90.

[92] K.J. Doores, Y. Mimura, R.A. Dwek, et al., Chem. Commun. 2006, 1401-3.

[93] N. Shangguan, S. Katukojvala, R. Greenberg, L.J. Williams, J. Am. Chem. Soc. 2003, 125, 7754-5.

[94] R. Huisgen, Angew. Chem., Int. Ed. Engl. 1963, 2, 565-98.

[95] F. Micheel, G. Baum, Chem. Ber. 1957, 90, 1595-6.

[96] C.W. Tornøe, C. Christensen, M. Meldal, J. Org. Chem. 2002, 67, 3057-64.

[97] V.V. Rostovtsev, L.G. Green, V.V. Fokin, K.B. Sharpless, Angew. Chem., Int. Ed. 2002, 41 , 2596-9.

[98] M. Meldal, C.W. Tornøe, Chem. Rev, 2008, 108, 2952-3015.

[99] R. Breinbauer, M. Köhn, ChemBioChem 2003, 4, 1147-9.

[100] N.J. Agard, J.A. Prescher, C.R. Bertozzi, J. Am. Chem. Soc. 2004, 126, 15046-7.

[101] X. Ning, J. Guo, Margreet A. Wolfert, G.-J. Boons, Angew. Chem., Int. Ed. 2008, 47, 2253-5.

[102] S.S. van Berkel, A.J. Dirks, M.F. Debets, et al., ChemBioChem 2007, 8, 1504-8.

[103] A.D. Moorhouse, J.E. Moses, ChemMedChem 2008, 3, 715-23.

[104] I.S. Carrico, Chem. Soc. Rev. 2008, 37, 1423-31.

[105] R.J. Pieters, D.T.S. Rijkers, R.M.J. Liskamp, QSAR \& Comb. Sci. 2007, 26, 1181-90.

[106] J.E. Moses, A.D. Moorhouse, Chem. Soc. Rev. 2007, 36, 1249-62.

[107] S. Dedola, S.A. Nepogodiev, R.A. Field, Org. Biomol. Chem. 2007, 5, 1006-17.

[108] F. Fazio, M.C. Bryan, O. Blixt, J.C. Paulson, C.-H. Wong, J. Am. Chem. Soc. 2002, 124, $14397-402$.

[109] M.C. Bryan, F. Fazio, H.-K. Lee, et al., J. Am. Chem. Soc. 2004, 126, 8640-1.

[110] D. Specker, V. Wittmann, Top. Curr. Chem. 2007, 267, 65-107.

[111] B.H.M. Kuijpers, S. Groothuys, A.R. Keereweer, et al., Org. Lett. 2004, 6, 3123-6.

[112] S. Groothuys, B.H.M. Kuijpers, P.J.L.M. Quaedflieg, et al., Synthesis 2006, 3146-52.

[113] H. Lin, C.T. Walsh, J. Am. Chem. Soc. 2004, I26, 13998-14003.

[114] S. Sen Gupta, K.S. Raja, E. Kaltgrad, E. Strable, M.G. Finn, Chem. Commun. 2005, 4315-17.

[115] S. Sen Gupta, J. Kuzelka, P. Singh, et al., Bioconjugate Chem. 2005, 16, 1572-9.

[116] G.A. Burley, J. Gierlich, M.R. Mofid, et al., J. Am. Chem. Soc. 2006, I28, 1398-9.

[117] J.C.M. van Hest, K.L. Kiick, D.A. Tirrell, J. Am. Chem. Soc. 2000, 122, 1282-8.

[118] K.L. Kiick, E. Saxon, D.A. Tirrell, C.R. Bertozzi, Proc. Natl. Acad. Sci. U.S.A. 2002, 99, 19-24.

[119] A.J. Link, D.A. Tirrell, J. Am. Chem. Soc. 2003, 125, 11164-5.

[120] A.J. Link, M.K.S. Vink, D.A. Tirrell, J. Am. Chem. Soc. 2004, 126, 10598-602.

[121] N. Budisa, Engineering the Genetic Code, Wiley-VCH, Weinheim, 2006.

[122] L. Wang, P. Schultz, Angew. Chem., Int. Ed. 2005, 44, 34-66. 
[123] A.J. Link, M.L. Mock, D.A. Tirrell, Curr. Opin. Chem. Biol. 2003, 14, 603-9.

[124] E. Saxon, C.R. Bertozzi, Science 2000, 287, 2007-10.

[125] F.L. Lin, H.M. Hoyt, H. Van Halbeek, R.G. Bergman, C.R. Bertozzi, J. Am. Chem. Soc. 2005, 127, 2686-95.

[126] M. Köhn, R. Breinbauer, Angew. Chem., Int. Ed. 2004, 43, 3106-16.

[127] S.I. van Kasteren, H.B. Kramer, H.H. Jensen, et al., Nature 2007, 446, $1105-9$.

[128] L. Merkel, H.S.G. Beckmann, V. Wittmann, N. Budisa, ChemBioChem 2008, 9, 1220-4.

[129] H. Lis, N. Sharon, Chem. Rev. 1998, 98, 637-74.

[130] D.C. Kilpatrick, Handbook of Animal Lectins: Properties and Biomedical Applications, John Wiley \& Sons Ltd, Chichester, 2000.

[131] H.-J. Gabius, H.-C. Siebert, S. André, J. Jiménez-Barbero, H. Rüdiger, ChemBioChem 2004, $5,740-64$.

[132] A. Varki, Glycobiology 1993, 3, 97-130.

[133] R.A. Dwek, Chem. Rev. 1996, 96, 683-720.

[134] D.H. Dube, C.R. Bertozzi, Nat. Rev. Drug Discovery 2005, 4, 477-88.

[135] H.-J. Gabius, Crit. Rev. Immunol. 2006, 26, 43-79.

[136] V. Wittmann, in Glycoscience: Chemistry and Chemical Biology, 2 ed. (eds.: B. Fraser-Reid, K. Tatsuta, J. Thiem), Springer-Verlag, Berlin, 2008, pp. 1771-93.

[137] Y.C. Lee, R.T. Lee, Acc. Chem. Res. 1995, 28, 321-7.

[138] J.M. Rini, Annu. Rev. Biophys. Biomol. Struct. 1995, 24, 551-77.

[139] K. Drickamer, Nat. Struct. Biol. 1995, 2, 437-9.

[140] M. Mammen, S.-K. Choi, G.M. Whitesides, Angew. Chem. Int. Ed. 1998, 37, 2754-94.

[141] R.T. Lee, Y.C. Lee, Glycoconjugate J. 2000, 17, 543-51.

[142] J.J. Lundquist, E.J. Toone, Chem. Rev. 2002, 102, 555-78.

[143] V. Wittmann, in Highlights in Bioorganic Chemistry: Methods and Applications (Eds.: C. Schmuck, H. Wennemers), Wiley-VCH, Weinheim, 2004, pp. 203-13.

[144] L.L. Kiessling, J.E. Gestwicki, L.E. Strong, Angew. Chem., Int. Ed. 2006, 45, 2348-68.

[145] F. Pérez-Balderas, M. Ortega-Muñoz, J. Morales-Sanfrutos, et al., Org. Lett. 2003, 5, $1951-4$.

[146] P. Wu, M. Malkoch, J.N. Hunt, et al., Chem. Commun. 2005, 5775-7.

[147] V. Ladmiral, G. Mantovani, G.J. Clarkson, et al., J. Am. Chem. Soc. 2006, 128, 4823-30.

[148] P. Appukkuttan, W. Dehaen, V.V. Fokin, E. Van der Eycken, Org. Lett. 2004, 6, 4223-5.

[149] A.K. Feldman, B. Colasson, V.V. Fokin, Org. Lett. 2004, 6, 3897-9.

[150] S. Chittaboina, X. Fang, Q. Wang, Tetrahedron Lett. 2005, 46, 2331-6.

[151] S. Fukuzawa, E. Shimizu, S. Kikuchi, Synlett 2007, 2436-8.

[152] K. Odlo, E.A. Høydahl, T.V. Hansen, Tetrahedron Lett. 2007, 48, $2097-9$.

[153] K. Barral, A.D. Moorhouse, J.E. Moses, Org. Lett. 2007, 9, 1809-11.

[154] H.S.G. Beckmann, V. Wittmann, Org. Lett. 2007, 9, 1-4.

[155] W.R. Carpenter, J. Org. Chem. 1962, 27, 2085-8.

[156] H. Quast, L. Bieber, Tetrahedron Lett. 1976, 17, 1485-6.

[157] M.M. Krayushkin, A.M. Beskopyl'nyi, S.G. Zlotin, O.A. Luk'yanov, V.M. Zhulin, Izv. Akad. Nauk SSSR, Ser. Khim. 1980, 2668.

[158] Z.P. Demko, K.B. Sharpless, Angew. Chem., Int. Ed. 2002, 41, 2110-13.

[159] Ibid., pp. 2113-16.

[160] P.A.S. Smith, J.M. Clegg, J.H. Hall, J. Org. Chem. 1958, 23, 524-9.

[161] R. Fusco, L. Garanti, G. Zecchi, J. Org. Chem. 1975, 40, 1906-9.

[162] L. Garanti, G. Zecchi, J. Org. Chem. 1980, 45, 4767-9.

[163] D. Korakas, A. Kimbaris, G. Varvounis, Tetrahedron 1996, 52, 10751-60.

[164] T.C. Porter, R.K. Smalley, M. Teguiche, B. Purwono, Synthesis 1997, 773-7.

[165] B.G. Davis, T.W. Brandstetter, L. Hackett, et al., Tetrahedron 1999, 55, 4489-500.

[166] M. Worch, V. Wittmann, Carbohydr. Res. 2008, 343, 2118-29.

[167] R. Apweiler, H. Hermjakob, N. Sharon, Biochim. Biophys. Acta 1999, 1473, 4-8.

[168] J.A. Prescher, C.R. Bertozzi, Cell 2006, 126, 851-4.

[169] J.A. Prescher, C.R. Bertozzi, Nat. Chem. Biol. 2005, I, 13-21.

[170] L.K. Mahal, K.J. Yarema, C.R. Bertozzi, Science 1997, 276, 1125-8. 
490 Organic Azides: Syntheses and Applications

[171] H.-C. Tai, N. Khidekel, S.B. Ficarro, E.C. Peters, L.C. Hsieh-Wilson, J. Am. Chem. Soc. 2004, 126, 10500-1.

[172] S.-G. Sampathkumar, A.V. Li, M.B. Jones, Z. Sun, K.J. Yarema, Nat. Chem. Biol. 2006, 2, 149-52.

[173] E. Saxon, S.J. Luchansky, H.C. Hang, C. Yu, S.C. Lee, C.R. Bertozzi, J. Am. Chem. Soc. 2002, 124, 14893-902.

[174] H.C. Hang, C. Yu, D.L. Kato, C.R. Bertozzi, Proc. Natl. Acad. Sci. U.S.A. 2003, 100, 14846-51.

[175] J.A. Prescher, D.H. Dube, C.R. Bertozzi, Nature 2004, 430, 873-7.

[176] D.H. Dube, J.A. Prescher, C.N. Quang, C.R. Bertozzi, Proc. Natl. Acad. Sci. U.S.A. 2006, 103, 4819-24.

[177] D.J. Vocadlo, H.C. Hang, E.-J. Kim, J.A. Hanover, C.R. Bertozzi, Proc. Natl. Acad. Sci. U.S.A. 2003, 100, 9116-21.

[178] P.V. Chang, J.A. Prescher, M.J. Hangauer, C.R. Bertozzi, J. Am. Chem. Soc. 2007, 129, 8400-1.

[179] M. Sawa, T.-L. Hsu, T. Itoh, et al., Proc. Natl. Acad. Sci. U.S.A. 2006, 103, 12371-6.

[180] D. Rabuka, S.C. Hubbard, S.T. Laughlin, S.P. Argade, C.R. Bertozzi, J. Am. Chem. Soc, 2006, 128, 12078-9.

[181] T.-L. Hsu, S.R. Hanson, K. Kishikawa, et al., Proc. Natl. Acad. Sci. U.S.A. 2007, 104, 2614-19.

[182] G. Wittig, A. Krebs, Chem. Ber. 1961, 94, 3260-75.

[183] N.J. Agard, J.M. Baskin, J.A. Prescher, A. Lo, C.R. Bertozzi, ACS Chem. Biol. 2006, I, 644-8.

[184] J.M. Baskin, J.A. Prescher, S.T. Laughlin, et al., Proc. Natl. Acad. Sci. U.S.A. 2007, 104, $16793-7$.

[185] J.A. Codelli, J.M. Baskin, N.J. Agard, C.R. Bertozzi, J. Am. Chem. Soc. 2008, 130, 11486-93.

[186] S.T. Laughlin, J.M. Baskin, S.L. Amacher, C.R. Bertozzi, Science 2008, 320, 664-7. 